\title{
Do New Neuroimaging Findings Challenge the Ethical Basis of Advance Directives in Disorders of Consciousness?
}

\author{
ORSOLYA FRIEDRICH, ANDREAS WOLKENSTEIN, RALF J. JOX, NIEK ROGGER, and \\ CLAUDIA BOZZARO
}

\begin{abstract}
Some authors have questioned the moral authority of advance directives (ADs) in cases in which it is not clear if the author of the AD is identical to the person to whom it later applies. This article focuses on the question of whether the latest results of neuroimaging studies have moral significance with regard to the moral authority of ADs in patients with disorders of consciousness (DOCs). Some neuroimaging findings could provide novel insights into the question of whether patients with DOCs exhibit sufficient psychological continuity to be ascribed diachronic personal identity. If those studies were to indicate that psychological continuity is present, they could justify the moral authority of ADs in patients with DOCs. This holds at least if respect for self-determination is considered as the foundation for the moral authority of ADs. The non-identity thesis in DOCs could no longer be applied, in line with clinical and social practice.
\end{abstract}

Keywords: disorders of consciousness; advance directives; personal identity; psychological continuity; neuroimaging

\section{Introduction}

There is an ongoing discussion about whether recent neuroimaging findings in patients with disorders of consciousness (DOCs) reveal partially intact consciousness not only in patients in minimally conscious states (MCS), but also in some patients in a clinically diagnosed vegetative state, recently renamed "unresponsive wakefulness syndrome" (UWS). ${ }^{1,2}$ The possibility of more intact consciousness in vegetative states than was previously understood or expected is not only relevant for clinical reasons, but may also be associated with ethical implications. New findings around consciousness in patients with DOCs could provide evidence that these patients still discharge one of the most discussed necessary criteria of diachronic personal identity, namely the psychological continuity criterion. The fulfillment of these criteria holds ethical importance, because diachronic personal identity is discussed by many philosophers as the basis for the moral authority of advance directives (AD). 3,4,5 Furthermore, DOCs suggest the possibility of borderline cases for philosophers, when discussing diachronic personal identity with a psychological approach. 6,7,8,9 Therefore, this article focuses on the question of whether the latest results of neuroimaging studies have moral significance with particular relation to the moral authority of ADs in patients with DOCs.

First, we will briefly introduce DOCs and recent neuroimaging findings that could allow for the interpretation of more or different states of consciousness, present in patients with DOCs. Then we will further outline additional considerations related to the moral authority of ADs and various understandings of

We thank Mary Clare O’Donnell for editing the manuscript. 
personal identity, before we move on to highlight the relevance of these new findings for psychological continuity. Finally, the connection between the moral authority of ADs and diachronic personal identity is discussed, as well as to what extent neuroscientific results have significance for the moral authority of ADs in patients with DOCs.

\section{Neuroimaging Findings in Patients with DOCs}

The designation DOC is used for patients with disturbed consciousness, attended by impaired verbal and motor responsiveness to diverse stimuli. ${ }^{10}$ In most cases, DOC is caused by acute and severe brain injury caused by head trauma, brain hemorrhages, or hypoxic brain injury. ${ }^{11}$ If the patient survives the coma and the patient's clinical situation stabilizes, an unresponsive wakefulness syndrome (UWS) or what was previously referred to as vegetative state (VS) can follow, with spontaneous breathing, alternating states of wakefulness (with open eyes) and sleep (with eyes closed), and with the ongoing absence of any kind of responsiveness. ${ }^{12,13}$ If reproducible signs of purposeful behavior can be identified in the patient; for example, when the eyes follow a moving object, or the patient begins to follow simple commands, we use the term MCS, with differing grades. ${ }^{14,15}$ Taken together, we refer to MCS and UWS as DOCs in cases in which we do not give further differentiation. Important to note, however, is another clinical condition, often confused with DOCs: the locked-in syndrome (LIS). In contrast to DOCs, patients with LIS have an intact awareness and cognition, yet motor functions are strongly reduced or completely lost. ${ }^{16}$

The diagnosis of DOCs primarily rests on clinical examination and validated behavioral test instruments (e.g., Coma Recovery Scale-Revised), supplemented by brain imaging and electroencephalography (EEG), the latter of which detects the electrical activity of superficial cortical neurons. ${ }^{17,18}$ The issue of prognosis in such cases and finding effective treatment for patients with DOCs is extremely difficult. ${ }^{19,20,21}$

Nevertheless, recent results in advanced neuroscience research could indicate real progress regarding the evaluation of consciousness in patients with DOCs. An increasing number of studies in the field tend to use neuroimaging techniques for DOCs, such as functional magnetic resonance imaging (fMRI) ${ }^{22} \mathrm{fMRI}$ results are based on the principle of neurovascular coupling, according to which active brain tissue recruits more (oxygenated) blood flow than inactive tissue. ${ }^{23}$ Blood oxygen level dependent response is also used in the relatively new technology of functional near infrared spectroscopy (fNIRS). Yet another functional brain imaging method applied in DOC studies is positron emission tomography (PET), which detects the metabolically active areas of the brain with the help of radioactively marked substances (usually glucose). ${ }^{24}$ The specific (dis-) advantages of the mentioned neuroimaging techniques in DOC are discussed in the article by Lorina Naci et al. ${ }^{25}$

Some general difficulties arise with applying neuroimaging technologies in DOCs. ${ }^{26,27,28}$ More relevant for our purposes are additional conceptual problems, given that there is little consensus about the nature and components of consciousness in philosophy, thus leaving it unclear as to which understanding of consciousness these empirical studies relate. It is further controversial in the philosophy of mind whether neural correlates give us answers to questions of consciousness at all. ${ }^{29}$ 
Olivia Gosseries et al. point out that neuroimaging studies in DOCs would require a theory of consciousness that describes both the fundamental features of consciousness and sufficient conditions for consciousness. ${ }^{30}$ Despite these pitfalls, we describe some relevant aspects of consciousness in the philosophical literature that could be more or less explicitly utilized with neuroimaging studies. Phenomenal consciousness, or the qualitative character of experiences, is one important aspect of consciousness in the philosophy of mind. ${ }^{31}$ Another candidate is access consciousness, defined as the subject's ability to access the representational content of his or her mental states. ${ }^{32,33}$ Still another aspect of consciousness is self-consciousness; that is, the reflective knowledge of a person experiencing him- or herself as someone who is in a certain mental state, and the ability for self-related reasoning or for conceiving of a future self. ${ }^{34} 35,36,37$ In neurological practice, the distinction between arousal (or wakefulness) and awareness seems more important. ${ }^{38}$

Leaving aside objections from the philosophy of mind concerning the relationship between visible neural activity and consciousness and the general difficulties of conceptualizing consciousness, we now can turn to the paradigms used by neuroimaging studies to detect consciousness in DOCs. We can distinguish two main paradigms: active and passive. In passive experiments, the patient has to do nothing in particular, there is no specific instruction; what is relevant is the spontaneous brain activity, or the reactivity to stimuli. ${ }^{39}$ The active paradigm requires the subject to perform a specific task. ${ }^{40}$ This active paradigm allows one to distinguish between willful brain activation after commands and reflexive brain activity, while bypassing (in usual actions necessary, but in DOCs impaired) motor output. ${ }^{41}$ Therefore, results from studies that operate on the active paradigm seem to provide reasonable evidence of consciousness. ${ }^{42,43}$ In one study, patients with DOC were asked to imagine familiar activities (playing tennis and walking through the rooms of one's house); some patients showed similar brain activation patterns to those of healthy persons. ${ }^{44,45}$ The distinct brain activation patterns in the two imagination scenarios could be used as a proxy for yes or no responses. In one case it was already noted that the patient was able to signal answers regarding personal questions using this yes-and-no code. ${ }^{46}$ There are also further studies that show a higher brain activation in the auditory cortex if patients with DOCs hear their own name, compared with noises or other (common) names. ${ }^{47,48,49}$ Although several of these studies show methodological limitations, their clinical impact on diagnosis and prognosis for patients with DOC can be immense. ${ }^{50,51}$ Active tasks or stimuli during neuroimaging could complement the diagnostic procedure and help to reduce misdiagnosis. ${ }^{52,53}$ Such results could — despite conceptual difficulties—also indicate the existence of more, or of a higher level of, consciousness in some patients with DOCs. Altered neuronal activity in cases when one's own name is spoken may, for example, indicate evidence for the existence of phenomenal consciousness, or for access consciousness. Moreover, increased neuronal activity during active mental imagery tasks could provide evidence for at least access consciousness, or could even be interpreted as evidence for self-reference and self-consciousness. ${ }^{54}$

Such findings and their interpretation could turn out to be also ethically relevant. Guy Kahane and Julian Savulescu have, for example, argued that results of neuroimaging about the existence of phenomenal consciousness in patients with DOCs could provide a strong moral reason for not saving the lives of patients with DOC. ${ }^{55,56}$ Carl Fisher and Paul Appelbaum have discussed in detail the broad 
scientific, legal, and ethical issues that might be related to the latest neuroimaging findings in DOCs. ${ }^{57}$ Jakob Hohwy and David Reutens called for more caution when confronted with the question of whether or not to withdraw life support in DOCs, if more consciousness in DOC is probable. ${ }^{58}$ They further argued that it would become even more important, in cases of potentially conscious patients, to ensure that suffering is alleviated. ${ }^{59}$ Orsolya Friedrich discusses that the knowledge of more intact consciousness in DOCs would influence end-of-life decisionmaking only from the background of certain theories of moral philosophy. ${ }^{60}$ In this article we focus more in depth on the question of whether the results of such neuroimaging studies could affect the existence of personal identity in cases of DOCs and, therefore, the moral authority of ADs in patients with DOCs. To be able to address this problem in greater detail, we will briefly introduce the relevant existing debate about ADs and diachronic personal identity.

\section{Moral Authority of ADs and Diachronic Personal Identity}

\section{Moral Authority of ADs}

Precedent autonomy becomes relevant when decisionmaking capacity is no longer present at time 2 (t2) in formerly (at time 1, t1) competent patients. ${ }^{61}$ If such persons were competent, and anticipated at $\mathrm{t} 1$ the future medical situation, and expressed their will or decisions for that specific situation, we call this form of will-expression an AD or living will. In general, we say: The AD is applicable, if the specific circumstances (e.g., prognosis, treatment options, or state of consciousness) match those the person described at $\mathrm{t} 1$ in his or her AD. For the validity of an AD, it is important that the AD was authored by the person him- or herself and truly represents the authentic will of this person. Details of AD applications are regulated, for example, in the English Mental Capacity Act 2005. ${ }^{62}$

However, there is an ongoing philosophical debate about the question of if and why ADs have a moral authority at $t 2 .{ }^{63,64,65,66,67}$ At first sight, the answer appears to be a clear "yes", because the application at $\mathrm{t} 2$ is exactly why the person composed his or her AD at $\mathrm{t} 1$. This logic has been questioned, however, by several authors in bioethics, as to whether ADs have moral authority in cases in which the necessary conditions of personal identity are not present at $t 2.68,69,70,71,72$ This critique seems plausible at least if we follow a line of argumentation for the moral authority of ADs, which focuses on securing the respect for the self-determination of the patient. ${ }^{73}$ Many philosophers agree that the moral authority of an AD results from its character of being an extension of the patient's right to self-determination. ${ }^{74}$ Therefore, they argue for the given moral necessity not to violate the precedent autonomous person's rights to self-determination and to stick to the AD, as long as there are no new, contradicting preferences expressed by the competent person. ${ }^{75,76,77}$

This line of argumentation depends on the presumption that at $\mathrm{t} 1$ and $\mathrm{t} 2 \mathrm{we}$ have the same person, which means that the AD applies to the same person at $\mathrm{t} 2$ as the one who wrote it at t1. Many influential publications discuss the relationship of diachronic personal identity, personhood, and the moral authority of ADs, with varying conclusions. ${ }^{78,79,80,81,82,83}$ The underlying question is the following: If the author of the $\mathrm{AD}$ at $\mathrm{t} 1$ was not identical with the human being at $\mathrm{t} 2$ (non-identity thesis), could this imply that the AD from $\mathrm{t} 1$ cannot be applied at $\mathrm{t} 2$ ? We do not aim 
to answer this question here, but rather seek to provide relevant considerations for proponents of the non-identity thesis regarding cases of DOCs and novel neuroimaging findings. Before we can address this issue further, we must clarify the definition of diachronic personal identity.

\section{Personal Identity}

Since the writings of John Locke, there has been an ongoing debate on how we can know that a person is identical at differing points in time ( $\mathrm{t} 1$ and $\mathrm{t} 2) .{ }^{84,85}$ One commonly suggested criterion for diachronic personal identity that is consistent with our everyday experience is that of the body, or the bodily criterion, in which the relation of personal identity is constituted by bodily identity ${ }^{86}$ For the bodily criterion the person one (P1) at $\mathrm{t} 1$ and the person $\mathrm{X}(\mathrm{PX})$ at $\mathrm{t} 2$ do not have to be materially identical across time, but the replacement of P1 by PX has to happen gradually. ${ }^{87}$ This seems to be the case in everyday life, but this intuitive experience cannot be taken as logically or conceptually necessary, as exceptional cases such as brain transplantation are at least imaginable. ${ }^{88,89}$ Therefore, the modified brain criterion of personal identity comes into play, as a result of the brain being the part of the body that is central for memory or personality. ${ }^{90}$ A further modification is the physical criterion: for personal identity it is necessary to have an identical brain that enables a person to live. ${ }^{91}$

John Locke made a significant contribution to the question of personal identity by presenting a different sort of criteria than those we have described. He postulated a memory criterion (which he called "consciousness") and argued that personal identity must be a question not of a substance, but rather of relation. ${ }^{92}$ Crucial for Locke as a criterion of personal identity would be "experience-memory" 93 which would involve our first person perspective and our awareness. ${ }^{94}$ The circularity objection shows that this criterion is challenging or problematic, because memory already presupposes personal identity, as we have to assume that the person must have done at $\mathrm{t} 1$, what that person remembers at $\mathrm{t} 2 .{ }^{95}$ To resolve this objection, Sydney Shoemaker introduced his concept of quasi-memories, which operates with the same characteristics as other concepts of memory. However, in the case of a quasi-memory, it is enough to have a belief that you did $X$, even if another person did X. ${ }^{96}$ Harold Noonan suggests a revised memory criterion as following: "P2 at t 2 is the same person as $\mathrm{P} 1$ at $\mathrm{t} 1$ just in case $\mathrm{P} 2$ at $\mathrm{t} 2$ is linked by continuity of experiencememory to $\mathrm{P} 1$ at $\mathrm{t} 1$." $^{\prime \prime 7}$

Other philosophers in line with Locke use a distinction between psychological connectedness and psychological continuity. ${ }^{98}$ Derek Parfit made this distinction prominent and defines psychological continuity as "the holding of overlapping chain of strong connectedness," 99 whereas "Psychological connectedness is the holding of particular direct psychological connections." ${ }^{100}$ Psychological connections, which function as an overlapping chain to psychological continuity, cannot only be seen in experience-memory, but also can be seen in unconscious causal links between childhood experiences and actual personality traits, or in persisting beliefs or desires, or in the connection between intentions and the acts they cause. ${ }^{101,102}$ However, determining a degree of sufficient connectedness can be a challenge.

Meanwhile, as would likely be intuitive for most people, a plain psychological continuity criterion seems to disregard the embodied character of the mind. Many combinations of criteria have been established in the philosophical literature. 
For example, it could be necessary for personal identity that a non-branching form of sufficient continued functioning of the same brain be present, which allows for a continuation of the psychological continuity. ${ }^{103,104}$

\section{Moral Authority of ADs in DOCs}

Following this short introduction to the different options for necessary criteria to define diachronic personal identity, we now turn to which of these criteria of personal identity can be ascribed to patients with DOCs. Patients with DOCs seem to satisfy the physical criterion of personal identity, as they possess a brain that is identical to that which they lived with previously. The issue becomes more difficult if one suggests that the psychological continuity criterion must be satisfied in order to be able to talk about personal identity. Proponents of the non-identity thesis might use that strategy and maintain that the psychological continuity criterion needs to be applied, but is not met. They conclude that because there is no psychological continuity, the resulting lack of personal identity destroys the moral authority of ADs. Various authors have stated that with the level of neurological damage seen in the case of most DOCs, and especially in UWS, personal identity is lost, because the necessary condition of psychological continuity is not present. ${ }^{105,106}$ If this is true, it depends on the level that we set as necessary for psychological continuity. We can set the threshold of psychological continuity very low; namely, to the degree that is required for persistence, which means every state other than brain death. ${ }^{107}$ If we set the limit that low, however, then we lose the difference from the physical criterion of personal identity.

If we regard psychological continuity as the relevant relation between states of personal identity, patients with DOCs present a more or less (depending on the threshold we set) existent challenge in terms of showing a sufficient continuity of states. Patients with DOCs, especially those with UWS, do not show clinical signs of psychological continuity with respect to criteria such as persisting beliefs, desires, intention, or memories. Exceptions are possible with cases in which patients meet these conditions, but in general, patients with DOCs do not possess a rich set of conscious states and do not show enough robust mental states. ${ }^{108}$ The topic is far from closed, however, as recent results from neuroimaging studies change the previous picture. For patients with DOCs, the "flickering flame of consciousness"109 documented in some patients in response to stimuli in new neuroimaging studies could emerge as relevant for psychological continuity, and as a condition of personal identity. Certain neuroimaging results could further be interpreted to suggest that, at least in some cases, patients with DOCs could intentionally reproduce imaginations from their past, recall names, and remember their old environment. If we could conclude with certainty from neuroscientific results that patients with DOCs show signs of intentional mental acting, which is connected to their past experiences, diachronic psychological continuity could be posited.

In light of this new evidence, we may go a step further to ask whether psychological continuity could also be claimed at a phenomenological level, even without necessarily involving higher cognitive capacities that allow for remembering or recalling past images or names. Diachronic unity of phenomenal consciousness seems to be a pivotal factor for psychological continuity. Phenomenal consciousness is characterized by its subjective experiential character, which can be described as its "phenomenal aspect" and a "nonstructural homogeneity" from a neuroscientific 
perspective. ${ }^{110,111,112,113,114}$ Neuroimaging studies show that phenomenal unity could still be retained in patients with DOCs, even if representational unity or access unity broke down. ${ }^{115}$ The question that remains for patients with DOCs is whether the "flickers of awareness" 116 in patients with DOCs show isolated states of consciousness or in fact offer evidence for a single stream of consciousness that is phenomenally unified. ${ }^{117}$ Further empirical studies are necessary to unequivocally determine diachronic phenomenal unity of consciousness.

Depending on the conception of personal identity, psychological continuity shown in neuroimaging results could create a major shift in influencing our ascription of personal identity to patients with DOCs. Findings for patients with DOCs, which indicate that psychological continuity is a given, could justify the moral authority of ADs in patients with DOCs, if the respect for self-determination is followed as a foundation for the moral authority of ADs. Relying on such positive neuroimaging findings, which indicate psychological continuity in patients with DOCs, the nonidentity thesis in DOCs could no longer be applied. Such findings could-in addition to conceptual objections - challenge the non-identity thesis, in line with clinical and social practice. Usually it is sufficient in practice if psychological continuity is created by the person at several points in time; it does not have to be present at every moment (e.g., deep sleep, fluctuating mental state). The person should, however, have the potential to always create this continuity. This opens up the option for UWS patients with a good rehabilitation prognosis to regain this continuity in a few weeks although at the moment they clearly cannot realize this continuity.

The general question of the dependence of the moral authority of ADs on diachronic personal identity cannot be solved, nor can the definitive criterion for personal identity be determined conclusively here. However, the recent empirical evidence in patients with DOCs demands a furthering of the ethical discussion, and a move beyond viewing DOCs merely as below-border cases for the nonidentity thesis. These results have moral significance, as they provide new possibilities for arguing for the moral authority of ADs in patients with DOCs.

\section{Conclusion}

In this article, we have asked whether recent findings in neuroimaging provide novel insights into the question of whether patients with DOC exhibit sufficient psychological continuity to be ascribed diachronic personal identity. A positive answer to this general question could have important consequences with regard to the ethical evaluation of ADs, because the argument from the non-identity thesis can no longer be put forward against the moral authority of ADs. The argument of non-identity holds that because a person issuing an $\mathrm{AD}$ at $\mathrm{t} 1$ is not identical to the person at $\mathrm{t} 2$, ADs have no moral authority. If, however, there is sufficient psychological continuity, as revealed by neuroimaging data, the non-identity thesis would no longer hold in these cases.

It should be stated, however, that in practice, these questions appear to occur only rarely in the way that they are discussed in philosophy. As articulated previously, people issue an AD precisely because they want to determine, at $\mathrm{t} 1$, certain courses of action when they cannot make decisions themselves anymore. From a first-person perspective, it therefore appears natural to assume diachronic identity between the person at $\mathrm{t} 1$ and $\mathrm{t} 2$. Of course, philosophically speaking, there are many conundrums to solve. In terms of philosophy's purpose, it should be clear 


\section{Orsolya Friedrich et al.}

that the phenomenological reality constitutes a goal toward which theorizing should strive. The aims of theoretical study must be situated in an ethical landscape that features strongly and widely held intuitions and practices, such as those associated with taking care of situations in which one can no longer decide for oneself. This means that it should be taken as one of the philosopher's central tasks to provide an explanation of real humans' experiences and expectations, apart from expounding and criticizing.

Empirical findings, such as those made possible through neuroimaging, provide novel access to the mind of a patient with DOC, and can contribute important building blocks toward this goal. Scientific evidence enhances the philosophical debate by suggesting paths toward strengthening human practice. There are cases, of course, where the empirical reality makes it necessary even to change human practice, but, as this article has intended to show, the case of DOC may not provide an example for this.

\section{Notes}

1. Owen AM, Coleman MR. Detecting awareness in the vegetative state. Annals of the New York Academy of Sciences 2008;1129:130-8.

2. Owen AM, Coleman MR. Functional neuroimaging of the vegetative state. Nature Reviews Neuroscience 2008;9(3):235-43.

3. Kahane G, Savulescu J. Brain damage and the moral significance of consciousness. The Journal of Medicine and Philosophy 2009;34(1):6-26.

4. Blustein J. Choosing for others as continuing a life story: The problem of personal identity revisited. Journal of Law, Medicine \& Ethics 1999;27(1):20-31.

5. Buchanan A, Brock D. Deciding for Others: The Ethics of Surrogate Decision Making. New York: Cambridge University Press; 1989.

6. See note 5, Buchanan, Brock 1989.

7. DeGrazia D. Human Identity and Bioethics. New York: Cambridge University Press; 2005.

8. McMahan J. The Ethics of Killing: Problems at the Margins of Life. New York: Oxford University Press; 2002.

9. Parfit D. Reasons and Persons. Oxford: Oxford University Press; 1984.

10. Bernat JL. Chronic disorders of consciousness. Lancet 2006;367(9517):1181-92.

11. Friedrich O, Jox RJ. Disorders of consciousness and the use of neurotechnologies-An ethical perspective. In: Johnson LSR, Karen S, eds. The Routledge Handbook of Neuroethics. London: Routledge; 2017:85-102.

12. Laureys S, Celesia GG, Cohadon F, Lavrijsen J, Leon-Carrion J, Sannita WG, et al. Unresponsive wakefulness syndrome: a new name for the vegetative state or apallic syndrome. BMC Medicine 2010;8:68.

13. Jennett B, Plum F. Persistent vegetative state after brain damage. A syndrome in search of a name. Lancet 1972;1(7753):734-7.

14. See note 11, Friedrich, Jox 2017.

15. Guldenmund P, Soddu A, Baquero K, Vanhaudenhuyse A, Bruno MA, Gosseries O, et al. Structural brain injury in patients with disorders of consciousness: A voxel-based morphometry study. Brain Injury 2016;30(3):343-52.

16. See note 11, Friedrich, Jox 2017.

17. See note 11, Friedrich, Jox 2017.

18. Bender A, Jox RJ, Grill E, Straube A, Lule D. Persistent vegetative state and minimally conscious state: a systematic review and meta-analysis of diagnostic procedures. Deutsches Ärzteblatt International. 2015;112(14):235-42.

19. See note 18, Bender et al. 2015.

20. Jox RJ, Bernat JL, Laureys S, Racine E. Disorders of consciousness: responding to requests for novel diagnostic and therapeutic interventions. The Lancet Neurology 2012;11(8):732-8.

21. Giacino JT, Fins JJ, Laureys S, Schiff ND. Disorders of consciousness after acquired brain injury: the state of the science. Nature Reviews. Neurology 2014;10(2):99-114. 


\section{Do New Neuroimaging Findings Challenge the Ethical Basis of ADs in DOCs?}

22. Fins JJ, Illes J, Bernat JL, Hirsch J, Laureys S, Murphy E. Neuroimaging and disorders of consciousness: Envisioning an ethical research agenda. American Journal of Bioethics 2008;8(9):3-12.

23. Fisher CE, Appelbaum PS. Diagnosing consciousness: Neuroimaging, law, and the vegetative state. Journal of Law Medicine \& Ethics 2010;38(2):374-85.

24. Stender J, Gosseries O, Bruno MA, Charland-Verville V, Vanhaudenhuyse A, Demertzi A, et al. Diagnostic precision of PET imaging and functional MRI in disorders of consciousness: A clinical validation study. Lancet 2014;384(9942):514-25.

25. Naci L, Monti MM, Cruse D, Kubler A, Sorger B, Goebel R, et al. Brain-computer interfaces for communication with nonresponsive patients. Annals of Neurologt 2012;72(3):312-23.

26. See note 11, Friedrich, Jox 2017.

27. Bonebakker AE, Bonke B, Klein J, Wolters G, Stijnen T, Passchier J, et al. Information processing during general anesthesia: Evidence for unconscious memory. Memory \& Cognition 1996;24(6): 766-76.

28. Davis MH, Coleman MR, Absalom AR, Rodd JM, Johnsrude IS, Matta BF, et al. Dissociating speech perception and comprehension at reduced levels of awareness. Proceedings of the National Academy of Sciences of the United State of America 2007;104(41):16,032-7.

29. Gosseries O, Di H, Laureys S, Boly M. Measuring consciousness in severely damaged brains. Annual Review of Neuroscience 2014;37:457-78.

30. See note 29, Gosseries et al. 2014.

31. See note 23, Fisher, Appelbaum 2010.

32. Hohwy J, Reutens D. A case for increased caution in end of life decisions for disorders of consciousness. Monash Bioethics Review 2009;28(2):14:1-12.

33. Block N. Consciousness and cognitive access. Proceedings of the Aristotelian Society 2008;108: 289-317.

34. See note 32, Hohwy, Reutens 2009.

35. Gallagher S, Dan Z. Phenomenological approaches to self-consciousness. In: Zalta EN, ed. Stanford Encyclopedia of Philosophy. Stanford: Metaphysics Research Laboratory; 2015.

36. Manary R. Intentionality and consciousness. In: Banks WP, ed. Encyclopedia of Consciousness. Oxford: Elsevier; 2009:417-29.

37. Siewert C. Consciousness and intentionality. In: Zalta EN, ed. The Stanford Encyclopedia of Philosophy; Stanford: Metaphysics Research Laboratory; 2011.

38. See note 23, Fisher, Appelbaum 2010.

39. See note 29, Gosseries et al. 2014.

40. See note 29, Gosseries et al. 2014.

41. See note 29, Gosseries et al. 2014.

42. See note 29, Gosseries et al. 2014.

43. See note 23, Fisher, Appelbaum 2010.

44. See note 29, Gosseries et al. 2014.

45. Monti MM, Vanhaudenhuyse A, Coleman MR, Boly M, Pickard JD, Tshibanda L, et al. Willful modulation of brain activity in disorders of consciousness. New England Journal of Medicine 2010;362(7):579-89.

46. See note 45, Monti et al. 2010.

47. Di HB, Yu SM, Weng XC, Laureys S, Yu D, Li JQ, et al. Cerebral response to patient's own name in the vegetative and minimally conscious states. Neurology 2007;68(12):895-9.

48. Staffen W, Kronbichler M, Aichhorn M, Mair A, Ladurner G. Selective brain activity in response to one's own name in the persistent vegetative state. Journal of Neurology, Neurosurgery, and Psychiatry 2006;77(12):1383-4.

49. Perrin F, Schnakers C, Schabus M, Degueldre C, Goldman S, Bredart S, et al. Brain response to one's own name in vegetative state, minimally conscious state, and locked-in syndrome. Archives of Neurology 2006;63(4):562-9.

50. See note 29, Gosseries et al. 2014.

51. See note 45, Monti et al. 2010.

52. Giacino JT, Hirsch J, Schiff N, Laureys S. Functional neuroimaging applications for assessment and rehabilitation planning in patients with disorders of consciousness. Archives of Physical Medicine and Rehabilitation 2006;87:67-76.

53. Gill-Thwaites H. Lotteries, loopholes and luck: Misdiagnosis in the vegetative state patient. Brain Injury 2006;20(13-14):1321-8.

54. See note 23, Fisher, Appelbaum 2010. 


\section{Orsolya Friedrich et al.}

55. See note 3, Kahane, Savulescu 2009.

56. Wilkinson DJ, Kahane G, Horne M, Savulescu J. Functional neuroimaging and withdrawal of lifesustaining treatment from vegetative patients. Journal of Medical Ethics 2009;35(8):508-11.

57. See note 23, Fisher, Appelbaum 2010.

58. See note 32, Hohwy, Reutens 2009.

59. See note 32, Hohwy, Reutens 2009.

60. Friedrich O. Knowledge of partial awareness in disorders of consciousness: Implications for ethical evaluations? Neuroethics 2013;6(1):13-23.

61. Davis JK. The concept of precedent autonomy. Bioethics 2002;16(2):114-33.

62. Mental Capacity Act 2005. London: The National Archives; 2012; available at https: / /www. legislation.gov.uk/ukpga/2005/9/contents (last accessed 3 June 2018).

63. See note 5, Buchanan, Brock 1989.

64. See note 7, DeGrazia 2005.

65. See note 61, Davis 2002.

66. Furberg E. Advance directives and personal identity: What is the problem? Journal of Medicine and Philosophy 2012;37(1):60-73.

67. Buford C. Advancing an advance directive debate. Bioethics 2008;22(8):423-30.

68. See note 4, Blustein 1999.

69. See note 5, Buchanan, Brock 1989.

70. See note 7, DeGrazia 2005.

71. See note 67, Buford 2008.

72. Dresser RS, Robertson JA. Quality of life and non-treatment decisions for incompetent patients: A critique of the orthodox approach. Journal of Law, Medicine E Ethics 1989;17(3):234-44.

73. See note 66, Furberg 2012.

74. See note 66, Furberg 2012.

75. See note 66, Furberg 2012.

76. Dworkin G. The Theory and Practice of Autonomy. Cambridge: Cambridge University Press; 1988.

77. Buchanan A. Advance directives and the personal identity problem. Philosophy and Public Affairs 1988;17(4):277-302.

78. See note 5, Buchanan, Brock 1989.

79. See note 7, DeGrazia 2005.

80. See note 9, Parfit 1984.

81. See note 66, Furberg 2012.

82. Dresser R. Advance directives, self-determination, and personal identity. In: Hackler C, Moseley R, Vawter DE, eds. Advance Directives in Medicine. New York: Praeger; 1989:155-70.

83. Kuczewski MG. Whose will is it, anyway? A discussion of advance directives, personal identity, and consensus in medical ethics. Bioethics 1994;8(1):27-48.

84. Locke J. An Essay Concerning Human Understanding. Original Edition 1689. Oxford: Oxford University Press; 2008.

85. Noonan H. Personal Identity. London: Routledge; 2003.

86. See note 85 , Noonan 2003.

87. See note 85 , Noonan 2003.

88. See note 85, Noonan 2003.

89. Williams BAO. Personal identity and individuation. Proceedings of the Aristotelian Society 1957;67: 229-52.

90. See note 85 , Noonan 2003.

91. See note 85 , Noonan 2003.

92. See note 84 , Locke 2008.

93. See note 85 , Noonan 2003 , at 9 .

94. See note 85, Noonan 2003.

95. See note 85 , Noonan 2003.

96. Shoemaker S. Identity, Cause, and Mind. Philosophical Essays. Cambridge: Cambridge University Press; 1984.

97. See note 85 , Noonan 2003 , at 10 .

98. See note 85, Noonan 2003.

99. See note 9, Parfit 1984, at 206.

100. See note 9, Parfit 1984, at 206.

101. See note 9, Parfit 1984. 
Do New Neuroimaging Findings Challenge the Ethical Basis of ADs in DOCs?

102. See note 85, Noonan 2003.

103. See note 7, DeGrazia 2005.

104. See note 8, McMahan 2002.

105. See note 5, Buchanan, Brock 1989.

106. See note 7, DeGrazia 2005.

107. See note 7, DeGrazia 2005.

108. Bayne T. The Unity of Consciousness. Oxford: Oxford University Press; 2012.

109. See note 108 , Bayne 2012, at 146

110. Metzinger T. Conscious Experience. Paderborn: Ferdinand Schoningh; 1995.

111. Northoff G. Qualia and the ventral prefrontal cortical function 'neurophenomenological' hypothesis. Journal of Consciousness Studies 2003;10(8):14-48.

112. Heinzel A, Moerth S, Northoff G. The central role of anterior cortical midline structures in emotional feeling and consciousness. Psyche 2010;16(2):23-47.

113. Chalmers DJ. The Conscious Mind: In Search of a Fundamental Theory. New York/Oxford: Oxford University Press; 1996.

114. Nagel T. What is it like to be a bat? Philosophical Review 1974;83:435-50.

115. See note 108, Bayne 2012.

116. See note 108 , Bayne 2012 , at 144

117. See note 108, Bayne 2012. 